\title{
Effect of Nitrite Toxicity on Histological Parameters to Fresh Water Fish "Cirrhinus Mrigala”
}

\author{
Yesudass Thangam \\ Assistant Professor \\ J.K.K.Nattraja college of Arts and Science, Kumarapalayam, Namakkal (Dt)
}

\begin{abstract}
Nitrite compound exerts environmental stress on fish. High levels of nitrite in water results in high stress levels leading to hyperventilation, elevated heart rate, increased blood pressure in fish. The present study was to evaluate the histopathological changes in liver exposed to nitrite toxicity during $7^{\text {th }}, 14^{\text {th }}, 21^{\text {st }}, 28^{\text {th }}$, and $35^{\text {th }}$, days respectively. Morphological structure of liver of Cirrhinus mrigala was presented in ( $\mathrm{Ph}$. m. 8). In the control fish, the liver showed hepatic cells located with central nucleus and homogenous cytoplasm. During acute treatment the liver exhibit disintegration of parenchymal cells, extensive vacuolation of parenchymal hepatocytes, degenerative cell and organelles and lumen with necrotic cells ( $\mathrm{Ph}$. m. 9). During sublethal treatment liver showed enlargements of hepatocytes, disintegration of cell boundaries of intercellular spaces, nuclear degeneration with pyknotic nucleus were noticed at the end of $7^{\text {th }}$ day $(\mathrm{Ph} . \mathrm{m} .10)$. At the end of $14^{\text {th }}$ day, disintegration of hepatocytes and necrosis of parenchymatous tissue noticed. The cell undergo necrosis or apoptosis. It is followed by karyorrhexis or fragmentation of the nucleus ( $\mathrm{Ph} . \mathrm{m} .11)$. The above said structural changes were severe at the end of $21^{\text {st }}$ and $28^{\text {th }}$, exposure period $(\mathrm{Ph} . \mathrm{m} .12,13)$. Complete rupture of hepatic cells, vacuolar degeneration, intercellular edema, were observed at the end of the treatment period ( $\mathrm{Ph} . \mathrm{m} .14)$.
\end{abstract}

Key Words: - Cirrhinus mrigala, Nitrite, Fish liver

\section{INTRODUCTION}

Nitrite toxicity to fish depends on the rate of nitrite accumulation, temperature, duration of exposure and ability of detoxification (Jensen 2003), and also depends on large number of factors, the most important is water chemistry especially chloride concentration (Lewis and Morris, 1996; Svobodova et al., 2005b). Aquatic organisms are normal, adapted to relatively low levels of nitrite in natural ecosystem often and natural concentration of inorganic nitrogenous compounds usually are not elevated. Therefore high levels of nitrite, nitrate and ammonia, are derived from human activities, are in pain and the ability of aquatic animals to service, grow and reproduce, resulting in direct (acute or chronic) toxicity of these in the nitrogenous compounds. An elevated ambient nitrite concentration is a potential problem for fresh water fish since nitrite is actively taken up across the gills in competition with chlorides. It is also well known toxicant for fish as well as a disrupter of multiple physiological functions including ion regulatory and respiratory, cardiovascular, endocrine and excretory processes (Eddy and Williams, 1987; Camargo et al., 2005a, Jesnen 2003, Camargo et al., 2005b).Nitrite is an intermediate component of nitrogenous compound and is a naturally occurring inorganic salt found in industrial effluent as a by product of corrosion inhibitors, production of explosives and used extensively in agriculture for crop fertilization. When used at low doses nitrite is toxic (Jensen 2003).

Histological changes in animal tissues provide a rapid method to detect effects of irritants, especially chronic ones, in various tissues and organs (Bernet et al., 1999). The potential utility of biomarkers for monitoring both environmental quality and the health of organisms inhabiting in the polluted ecosystem has received increasing attention the last years. Fish are useful experimental models that have been widely used to evaluate the health of aquatic ecosystems and toxicologic pathology (Korkmaz et al., 2009). Histopathological analysis has already been tested and proposed as an efficient and sensitive tool to the monitoring of fish health and environmental pollution in natural water bodies (Teh et al., 1997; Steniford et al., 2003). Histopathology is an important component of several measures of fish health and histopathological markers have been recommended for field application, more often as a generalized, nonspecific response to several stressful stimuli (Teh et al., 1997).

In fish among various organs liver plays an important role in vital functions in basic metabolism and it is the major organ of accumulation, biotransformation, and excretion of contaminants in fish (Wu et al., 2008). Histopathology of fish liver is a monitoring tool that can provide an assessment of the effects of environmental stressors on fish populations, and it was proposed to be one of the most reliable (Hinton and Lauren, 1990; Fernandes et al., 2008). Brusle et al. (1996) stated that fish liver histology could serve as a model for studying the interactions between environmental factors and hepatic structures and functions. Changes in liver histologic structure testify the development of cirrhosis or lipoid degeneration of liver (Moiscenko, 2005). Battacharya et al. (1975) in Clarias batrachus and Konar (1970) in Labeo rohita observed histopathological changes in liver like 
liver cord disarray, vacuolization and necrosis of liver treated with endrin, industrial pollutants and sevin, respectively. Pane et al. (2004) observed a significant contraction of the lamellar vasculature following tributylin compounds and nickel. Histological changes in liver of Oreochromis mossambicus exposed to cadmium and zinc shows hyalinization, hepatic vacuolation cellular swelling and congestion of blood vessels (Van Dyk et al., 2007). Pathological findings in the liver of fish exposed to mercury include lipid peroxidation with enhanced content of ceroid/lipofucsin, necrosis, increased number and size of macrophage aggregates or alterations in cytoplasmic organization (Meinelt et al., 1997; Oliveira-Ribeiro et al., 2002). Similar results have also been reported by many authors (Rabito et al., 2005; Venkateshwara Rao, 2006; Coimbra et al., 2007; Korkmaz et al., 2009).

\section{MATERIALS AND METHODS}

Histopathological profiles of liver were studied by the methods Pearse (1968), Roberts (1978) and Humason (1979). The changes in physico-chemical characteristics, such as temperature, $\mathrm{pH}$, Dissolved oxygen, alkalinity, hardness, salinity, calcium and magnesium of experimental water were recorded throughout the experimental period. Freshwater fish Cirrhinus mrigala, weighing 5.0-6.0 gm and measuring 7-8 cm were collected from Tamilnadu fisheries development corporation limited, Aliyar fish farm, Aliyar, Tamilnadu, India. Fish of same age and size which hatched from the same lot of eggs were collected, the age of fish being 2 to 3 months old. They were safely brought to the laboratory in well packed polythene bags containing aerated water and stocked in a large cement tanks (36' $\left.\mathrm{x} 18^{\prime} \times 19^{\prime}\right)$. Fish were acclimatized for about 20 days before the commencement of the experiment. During acclimatization period, fish were fed with ad libitum, with rice bran and ground nut oil cake in the form of dough once in daily. Water replaced every $24 \mathrm{~h}$ after feeding in order to maintain a healthy environment for the fish. This ensures sufficient oxygen supply for the fish and the environment is devoid of any accumulated metabolic waste. The feeding was withheld for $24 \mathrm{~h}$ before the commencement of the experiment and to keep the specimens in the same metabolic state. The fish were introduced into glass aquarium (26'x18'x18.5') $\mathrm{cm}$ which was washed thoroughly and maintained in the laboratory. Separate circular plastic tubs of 50 litres of water capacity were taken and different concentrations of nitrite were added. 10 healthy fishes were introduced into each tub. A control tub (no toxicant) with 50 litres of water and 10 fishes were also maintained. Three replicates were maintained for each concentration groups. The mortality/ survival of fish in control and nitrite treated tubs was recorded after $24 \mathrm{~h}$ and the concentration at which $50 \%$ mortality of fish occurred was taken as the median lethal concentration (Lc50) for $24 \mathrm{~h}$. Sublethal values were found to be $28.31 \mathrm{ppm}$. For histopathological studies fish were treated with nitrite and various steps were followed for this study. Fixation, washing, dehydration, clearing, infiltration, embedding, sectioning, staining.

\section{FIXATION}

The kidney were dissected out from the control and nitrite treated fish were cut into bits of 1 to $2 \mathrm{~cm}$ in diameter. These tissues were immediately put in Bouin's fluid for $24 \mathrm{~h}$ to avoid post-mortem changes and shrinkage during further process like dehydration, embedding and sectioning.

\section{WASHING}

After fixation the tissues were taken and the excessive fixative was removed by transferring the tissues to $50 \%$ alcohol (to prevent interference with subsequent process).

\section{DEHYDRATION}

In dehydration process the tissues were put into alcohol series like 30\%, 50\%, 70\%, 90\% and absolute alcohol and duration of $30 \mathrm{~min}$. was given in each alcohol series. To ensure complete removal of water from the tissues a minimum of two or three changes were given in absolute alcohol at an interval of 30 minutes.

\section{CLEARING}

During clearing alcohol was replaced from the tissues by using a clearing agent xylene. The tissues were kept in xylene for about 30 min to $1 \mathrm{~h}$ until they become transparent.

\section{INFILTRATION}

During infiltration the tissues were kept in a paraffin embedding bath (metal cups filled with paraffin at $58-60^{\circ} \mathrm{C}$ ). Then the tissues were transferred directly from xylene to molten paraffin. A minimum of three changes were given in paraffin wax with 30 minutes duration in each. 


\section{EMBEDDING}

For embedding, L blocks were filled with molten paraffin wax. Then the tissues were placed with proper orientation. After embedding process, the blocks were kept in water overnight to ensure complete solidification. Finally, blocks were removed for sectioning.

\section{SECTIONING}

Tissues were cut with $7 \mu$ thickness using a rotator microtome. Then the sections were spread on a glass slide using egg albumin as an adhesive. After complete spreading, the sections were placed in an oven overnight at $37^{\circ} \mathrm{C}$ and the sections were taken for staining.

\section{STAINING}

During staining paraffin wax from the sections was removed by dewaxing using xylene. Then the sections were hydrated by immersing in descending grades of alcohol (absolute alcohol, 90\%, 70\%, 50\%, 30\%) for about 1-2 min. in each. Then, the sections were stained in Heidenhain's iron

haematoxylin stain for 2 to $5 \mathrm{~min}$, washed in tap water until the sections become bluish black in colour and then stained in $1 \%$ Eosin.

For destaining, $1 \%$ iron alum was used. The sections were dehydrated through ascending grades of alcohol $(30 \%, 50 \%, 70 \%, 90 \%$, absolute alcohol) for about 5 sections in each. Subsequently, the sections were cleared in xylene and mounted permanently with cover glass using DPX mountant. The histological results of gills of fish from control and nitrite treated were given as photomicrographs in appropriate places in the text.

\section{RESULTS}

Morphological structure of liver of Cirrhinus mrigala was presented in (Ph. m. 8). In the control fish, the liver showed hepatic cells located with central nucleus and homogenous cytoplasm. During acute treatment the liver exhibit disintegration of parenchymal cells, extensive vacuolation of parenchymal hepatocytes, degenerative cell and organelles and lumen with necrotic cells (Ph. m. 9). During sublethal treatment liver showed enlargements of hepatocytes, disintegration of cell boundaries of intercellular spaces, nuclear degeneration with pyknotic nucleus were noticed at the end of $7^{\text {th }}$ day $(\mathrm{Ph} . \mathrm{m} .10)$. At the end of $14^{\text {th }}$ day, disintegration of hepatocytes and necrosis of parenchymatous tissue noticed. The cell undergo necrosis or apoptosis. It is followed by karyorrhexis or fragmentation of the nucleus ( $\mathrm{Ph} . \mathrm{m} .11)$. The above said structural changes were severe at the end of $21^{\text {st }}$ and $28^{\text {th }}$, exposure period (Ph. m. 12, 13). Complete rupture of hepatic cells, vacuolar degeneration, intercellular edema, were observed at the end of the treatment period ( $\mathrm{Ph} . \mathrm{m} .14)$.
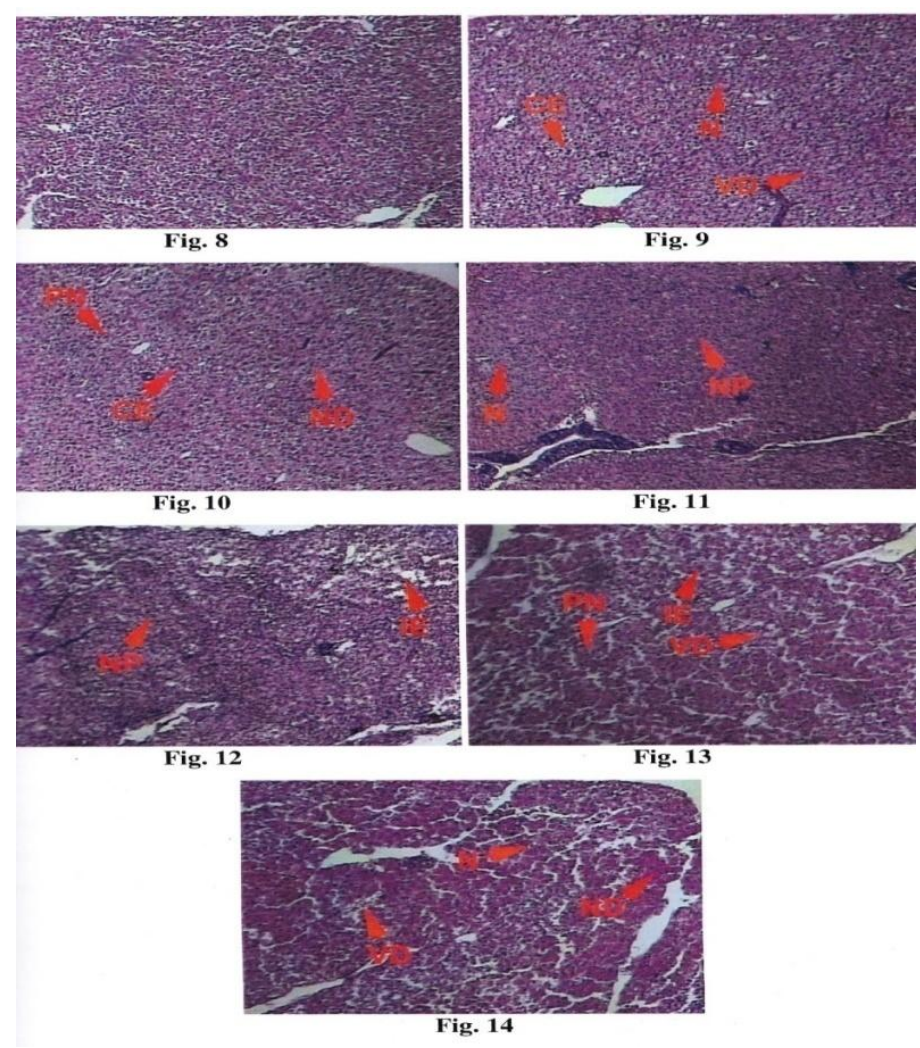
Fig 8 -14. (8) Liver structure of control fish. H\&E, x 100,

(9) Liver tissue of C.mrigala exposed to $28.31 \mathrm{ppm}$ of nitrite for $24 \mathrm{~h}$ (acute): CE cellular edema; N: necrotic hepatocytes; VD: vacuolar degeneration. H\&E, x 100.

(10) Liver tissue of C.mrigala exposed to $2.831 \mathrm{ppm}$ of nitrite for 7 days (sublethal); PN: pyknotic nucleus; CE: cellular edema; ND: nuclear degeneration $\mathrm{H} \& \mathrm{E}, \mathrm{x} 100$.

(11) Liver tissue of C.mrigala exposed to $2.831 \mathrm{ppm}$ of nitrite for 14 days (sublethal); N: necrotic hepatocytes; NP: nuclear pycnosis. H\&E, x 100.

(12) Liver tissue of C.mrigala exposed to $2.831 \mathrm{ppm}$ of nitrite for 21 days (sublethal); NP: nuclear pycnosis; IE: intercellular edema. H\&E, x 100.

(13) Liver tissue of C.mrigala exposed to $2.831 \mathrm{ppm}$ of nitrite for 28 (sublethal); PN: pyknotic nucleus; IE: intercellular edema; VD: vacuoler degeneration. H\&E, x 100.

(14) Liver tissue of C.mrigala exposed to $2.831 \mathrm{ppm}$ of nitrite for 35 (sublethal); N: necrotic hepatocytes; ND: nuclear degeneration; VD: vacuole degeneration. H\&E, x 100

\section{DISCUSSION}

Liver being the main organ of various key metabolic pathways, toxic effects of chemicals usually appear primarily in the liver (Benli et al., 2008). The organ most associated with detoxification and biotransformation process is the liver, and due to its function, position and blood supply (Van der Oost et al., 2003). It is also one of the organs most affected by contaminants in the water (Rodrigues and Fanta, 1998). Stentiford et al. (2003) and Stehr et al. (2004) observed that toxicopathic liver lesions in fish species are effective biological markers of chemical exposures. In the present study during acute and sublethal treatment the liver of Cirrhinus mrigala showed various alterations such as irregular shaped nuclei, nuclear hypertrophy, nuclear vacuolation and vacuolization of the hepatocytes. Similarly, cytoplasm and nuclear degeneration were also noticed. Anomalies, such as irregular shaped hepatocytes cytoplasmic vacuolation and nucleus in a lateral position, close to cell membrane, were described in the Siluriform corydoras and Paleatus contaminated by organophosphates pesticides (Fanta et al., 2003). Histological response in zinc exposed specimens with the most prevalent histological characteristics identified being hyalinization of hepatocytes, increased vacuolation associated with lipid accumulation, congestion of blood vessels, and cellular swelling (Hinton and Lauren, 1990; Van Dyk et al., 2007). The hexavalent chromium exposure exhibited marked degenerative changes in the liver tissues (Mishra and Mohanty, 2008). The presence of necrosis is in the fact one of most visible damages in tissues affected by a pollutant (Rabitto et al., 2005; Mela et al., 2007). Pacheco and Santos (2002) described increased vacuolization of the hepatocytes as a signal of degenerative process that suggest metabolic damage, possibly related to exposure to contaminated water.

Non-neoplastic lesions, such as cellular and nuclear polymorphism have been considered as an initial toxicopathic lesion resulting from exposure to toxic agents (Stentiford et al., 2003). Hepatocellular necrosis has been observed as most pronounced in fish collected in contaminated ecosystems and was considered as response to metal exposure (Olojo et al., 2005). According to Schmalz et al. (2002) the presence of necrotic areas in liver of Fundulus heteroclitus exposed to mercury and other heavy metals was related to the increase of 
an inflammatory response and formation of MMCs. Au (2004) reported that histopathological lesions in liver are not specific to pollutants; nevertheless there are numerous reports of histo-cytopathological changes in liver of fish exposed to a wide range of organic compounds and heavy metals (Braunbeck, 1998; Jimenez-Tenorio et al., 2007). Agents that produce liver injury can be placed in two broad categories (Klatskin, 1969), those agents that produce toxic hepatitis and those that produce drug-induced hepatitis. According to Plaa (1980), the substance that produce toxic hepatitis have the following common characteristics: (1) they produce a distinctive lesion, (2) the severity of the lesions seems to be related to the dose administered (3) while quantitive differences in potency can be found among individuals, generally the same lesion can be produced in all individuals and (4) they usually appear after a predictable, usually brief, latent period. The factors which are involved in liver injury are biotransformation of toxicants, alteration of hepatic blood flow and potentiation of hepatotoxicity. The occurrence percentages of the histopathological changes in the livers are more widespread (Ayas et al., 2007).

\section{REFERENCE}

[1] Au, D.W.T., 2004. The application of histo-cytopathological biomarkers in marine pollution monitoring: a review. Mar. pollut. Bull., 48: 817-834.

[2] Ayas, Z., Ekmekci, G., Ozmen, M., Yerli, S.V., 2007. Histopathological changes in the livers and kidneys of fish in Sariyar Reservoir, Turkey. Environ Toxicol. Pharmacol., 23, 242-249.

[3] Benli, A.C.K., Koksal, G., Ozkul, A., 2008. Sublethal ammonia exposure of Nile tilapia (Oreochromis niloticus L). Effects on gill, liver, kidney histology. Chemosphere. 72, 1355-1358.

[4] Bernet. D., Schmidt, H., Meier, W., Burkhardt-holm, P., Wahli, T., 1999. Histopathology in fish: proposal for a protocol to assess aquatic pollution. J. Fish. Dis., 22, 25-34.

[5] Bhattacharya, S., Mukherjee, S., Bhayyacharya, S., 1975. Toxic effects of endrin on hepatopancreas on the teleost fish, Clarias batrachus (Linn.). Indian J. Exp. Biol., 13, 185-186.

[6] Braunbeck, T., 1998. Cytological alterations in fish hetatocytes following in vivo and in vitro sublethal exposure to xenobiotics-structural biomarkers of environmental contamination. In: Braunbeck, T., Streit, B., Hinton, D.E., Editors, 1998. Fish Ecotoxicology, Birkhauser Verlag, Switzerland, pp. 61-140.

[7] Brusle, I., Gonzalez, I., Anadon, G., Munishi, J.S.D., Dutta, H. M., 1996. In: Fish Morphology, the structure and function of liver (Eds.). Science Publishers Inc, New York, pp. 351.

[8] Camargo, J.A., Alonso, A., Puente, M. D. L., 2005b. Eutrophication downstream from small reservoirs in mountain rivers of central spain. Water Res., 39, 3376-3384.

[9] Coimbra, A.M., Reis-Henriques, E.M.A., 2007. Tilapia larvae aroclor 1254 exposure: Effects on gonads and circulating thyroid hormones during adulthood. Bull. Environ. Contam. Toxicol., 79, 488-493.

[10] Eddy, F.B., Williams, E.M., 1987. Nitrite and fresh water fish. Chem. Ecol., 3, 1-38.

[11] Fanta, E., Rios, F.S., Romao, S., Vianna, A.C.C., Freiberger, S., 2003. Histopathology of the fish Corydoras paleatus contaminated with sublethal levels of organophosphorus in water and food. Ecotoxicol. Environ. Saf., 54, 119-130.

[12] Fernandes, C., Fontainhas-Fernandes, A., Rocha, E., Salgado, M.A., 2008. Monitoring pollution in esmoriz-paramos lagoon, Portugal: Liver histological and biochemical effects in Liza saliens. Environ. Monit. Assess., 145(1-3), 315-322.

[13] Hinton, D.E., Lauren, D.J., 1990. Liver structural alterations accompanying chronic toxicity in fishes: potential biomarkers of exposure. In: Biomarkers of Environmental Contamination. McCarthy, J.F., Shugart, L.R., (Eds.). Lewis Publication., Boca Raton, pp. 17-57.

[14] Humason, G.L., 1979. Animal Tissue Techniques, (4 ${ }^{\text {th }}$ Ed.), W.H. Freeman and Company, San Francisco, California, pp. 661.

[15] Jensen, F,B., Nitrite disrupts multiple physiological functions in aquatic animals. Comp Biochem Physiol. A, 135, 9-24.

[16] Jimenez-Tenorio, N., Morales-Caselles, C., Kalman, J., Salamanca, M.J., Gonzalez de Canales, M.L., Sarasquete, C., DelValls, T.A., 2007. Determining sediment quality for regulatory proposes using fish chronic bioassays. Environ. Int., 33, 474-480.

[17] Klastin, G., 1969. Toxic and drug-induced hepatitis. In: L. Schiff, Diseases of the Liver, (3 ${ }^{\text {rd }}$ Ed.). J.B. Lippincott Co., Philadelphia, pp. 498-601.

[18] Konar, S.K., 1970. Some effects of sublethal levels of heptachlor on rohu, Labeo rohita. J. Inland Fish. Soc. India., 2, 51-54.

[19] Korkmaz, N., Cengiz, E.I., Unlu, E., Uysal, E., Yanar, M., 2009. Cypermethrin-induced histopathological and biochemical changes in Nile tilapia (Oreochromis niloticus), and the protective and recurperative effect of ascorbic acid. Environ. Toxicol. Pharmacol., 28(2), 198-205.

[20] Lewis, W.M., Morris, D.P., 1986. Toxicity of nitrite to fish: a review. T. Am. Fish. Soc., 115, 183-199. 
[21] Meinelt, T., Schreckenbach, K., Stueber, A., Steinberg, C., 1997. Fish toxicity of nitrite. Fish Teichwirt., 48, 421-426.

[22] Mela, M., Randi, M.A.F., Ventura, D.F., Carvalho, C.E.V., Pelletier, E., Oliveira Ribeiro, C.A., 2007. Effects of dietary methylmercury on liver and kidney histology in the neotropical fish Hoplias malabaricus. Ecotoxicol. Environ. Saf., 68(3), 426-435.

[23] Mishra, A.K., Mohanty, B., 2008. Acute toxicity impacts of hexavalent chromium on behavior and histopathology of gill, kidney and liver of the freshwater fish, Channapunctatus (Bloch). Environ. Toxicol. Pharmacol., 26, 136-141.

[24] Moiscenko, T.I., 2005. Ecotoxicological Approach to Water Quality Assessment. Water Resour., 32(2), 163-174.

[25] Oliveira Ribeiro, C.A., Belger, L., Pelletier, E., Rouleau, C., 2002. Histopathological evidence of inorganic mercury and methyl mercury in the Arctic charr (Salvelinus alpines). Environ. Res., 90, $217-$ 225.

[26] Olojo, E.A.A., Olurin, K.B., Mbaka, G., Oluwemimo, A.D., 2005. Histopathology of gills and liver tissues of the African catfish Clarias gariepinus exposed to lead. Afr. J. Biotechnol., 4(1), 117-122.

[27] Pacheco, M., Santos, M.A., 2002. Biotransformation, genotoxic and histopathological effects of environmental contaminants in European ell (Anguilla Anguilla L.). Ecotoxicol. Environ. Safe., 53, 331347.

[28] Pane, E.F., Haque, A., Goss, G.G., Wood, C.M., 2004. The physiological consequences of exposure to chronic, sublethal waterborne nickel in rainbow trout (Oncorhynchus mykiss): exercise vs, resting physiology. J. Exp. Bio., 207, 1249-1261.

[29] Pearse, A.G.E., 1968. Histochemistry. Theoretical and applied. Vol-1 ( ${ }^{\text {rd }}$ Eds), J\& A. Churchill Ltd., London, pp. 13-102.

[30] Plaa, G.L., 1980. Toxic responses of the liver. In: Casarett and Doull's Toxicology. The basic science of poisons. Doull, J., Klaasen, C.D., Amdur, M.O., (Eds.), Macmillan Publishing Co. Inc., New York, pp. 206-226.

[31] Rabitto, I.S., Alves Costa, J.R.M., Silva de Assis, H.C., Pelletier, E., Akaishi, F.M., Anjos, A., 2005. Effects of dietary $\mathrm{Pb}$ (II) and tributylin on neotropical fish, Hoplias malabaricus: histopathological and biochemical findings. Ecotoxicol. Environ. Saf., 60, 147-156.

[32] Roberts, R.J., 1978. The pathophysiology and systematic pathology of teleosts, and laboratory methods. In: Fish pathology. (Ed), Bailliere Tindall., London, 67, pp. 235-246.

[33] Rodrugues, E.L., Fanta, E., 1998. Liver histopathology of the fish Brachydanio rerio after acute exposure to sublethal levels of the organophosphate Dimetoato 500. Revista Brasileria de Zoologia, 15, 441-450.

[34] Schmalz, W.F., Hernandez Jr., A.D., Weis, P., 2002. Hepatic histopathology in two populations of the mummichog, Fundulus. Mar. Environ. Res., 54(3-5), 539-542.

[35] Stehr, C.M., Myers, M.S., Johnson, L.L., Spencer, S., Stein, J.E., 2004. Toxicopathic liver lesions in English sole and chemical contaminant exposure in Vancouver Harbour, Canada. Mar. Environ. Res., 57, 55-74.

[36] Stentiford, G.D., Longshaw, M., Lyons, B.P., Jones, G., Green, M., Feist, S.W., 2003. Histopathological biomarkers in estuarine fish species for the assessment of biological effects of contaminants. Mar. Environ. Res., 55, 137-159.

[37] Svobodova, Z., Machova, J., Drastichova, J., Groch, L., Luskova, V., Poleszczuk, G., Velisek, J., Kroupova, H., 2005b. Haematological profile of carp blood following nitrite exposure at different concentration of chloride. Aquacult. Res., 36, 1177-1184.

[38] Teh, S.J., Adams, S.M., Hinton, D.E., 1997. Histopathologic biomarkers in feral freshwater fish populations exposed to different types of contaminant stress. Aquat.Toxicol., 37, 51-70.

[39] Van der Oost, R., Beber, J., Vermeulen, N.P.E., 2003. Fish bioaccumulation and biomarkers in environmental risk assessment. Environ. Toxicol.Pharmacol. 13, 57-149.

[40] Van Dyk, J.C., Pieterse, G.M., Van Vuren, J.H.J., 2007. Histological changes in the liver of Oreochromis mossambicus (Cichlidae) after exposure to cadmium and zinc. Ecotoxicol. Environ. Saf., 66, 432-440.

[41] Venkateshwara Rao, J., 2006. Biochemical alterations in euryhaline fish, Oreochromis mossambicus exposed to sub-lethal concentrations of an organophosphorus insecticide, monocrotophos. Chemosphere, 65(10), 1814-1820.

[42] Wu, J.P., Chen, H.C., Huang, D.J., 2008. Histopathological and biochemical evidence of hepatopancreatic toxicity caused by cadmium and zinc in the white shrimp, Litopenaeus vannamei. Chemosphere, 73, 1019-1026. 